\title{
Kelimpahan Spesies Kelelawar Ordo Chiroptera di Gua Wilayah Selatan Pulau Lombok NTB
}

\author{
Oleh: \\ Siti Rabiatul Fajri ${ }^{1}$, Agil Al Idrus ${ }^{2}$, dan Gito Hadiprayitno ${ }^{2}$ \\ ${ }^{1)}$ Program Pascasarjana Magister Pendidikan IPA Universitas Mataram \\ ${ }^{2}$ Program Studi Pendidikan Biologi FKIP Universitas Mataram \\ Email: rabiatul_fajri@yahoo.com
}

\begin{abstract}
ABSTRAK
Penelitian untuk mengetahui kelimpahan kelelawar di beberapa gua di wilayah selatan Pulau Lombok telah dilakukan. Survey dilakukan selama bulan Maret sampai Mei 2014 pada 5 gua yaitu Gua Gale-Gale, Gua Buwun, Gua Kenculit, Gua Raksasa, dan Gua Pantai Surga. Pengambilan sampel kelelawar untuk identifikasi dilakukan dengan menggunakan Mist net (jaring kabut). Kelelawar yang tertangkap diidentifikasi lebih lanjut di Laboratorium Biologi FMIPA Universitas Mataram. Hasil penelitian menunjukkan, bahwa ada 6 Famili dengan 12 spesies.Spesies tersebut diantaranya; Hipposederos ater memiliki kelimpahan yang paling tinggi $(18,1$ individu/trap/malam) dibandingkan dengan kelimpahan spesies kelelawar yang lain. kemudian diikuti secara berturut-turut oleh Rhinolopus simplex (10,3 individu/trap/malam), Rosettus amplxicaudatus (7,5 individu/trap/malam), Miniopterus pusillus (7,3 individu/trap/malam), Hipposideros diadema (6,7 individu/trap/malam), Eonicteris speleae (6.2 individu/trap/malam), Phoniscus atrox dan Taphozous melanopogon (masing-masing memiliki kelimpahan 5,2 individu/trap/malam), Macroglossus minimus (4,5 individu/trap/malam), Murina cyclotis (4,3 individu/trap/malam), Rhinopoma microphyllum (2,7 individu/trap/malam), dan Hipposideros bicolor (1,1 individu/trap/malam). Kelimpahan spesies kelelawar tertinggi ditemukan di Gua Raksasa Tanjung Ringgit dengan kelimpahan sebesar 27,5 individu/trap/malam. Selanjutnya diikuti oleh Gua Gale-gale 25,3 individu/trap/malam, Gua Buwun 9,3 ind/Trap.malam, gua Pantai Surga 8,7 individu/trap/malam, dan gua Kenculit 8,2 individu/trap/malam.
\end{abstract}

Kata Kunci: Kelelawar, Gua, Wilayah Selatan Pulau Lombok

\begin{abstract}
A research on diversity of bats of cave in the south area of Lombok island was conducted. Five caves survied for this research were Gale-Gale, Buwun, Kenculit, Raksasa, and cave Pantai Surga. Survey was done during Mart to Mei 2014. Samples of bat were obtained by using Mist net. The bats were observed and identified in the Biology Laboratorium FMIPA University of Mataram. This research fully identified 12 species from 6 Famili of bats. The species are such as: Hipposederos ater, Rhinolopus simplex, Rosettus amplxicaudatus, Miniopterus pusillus, Hipposideros diadema, Eonicteris speleae, Phoniscus atrox, Taphozous melanopogon, Macroglossus minimus, Murina cyclotis, Rhinopoma microphyllum, and Hipposideros bicolor. The highest density was recorded for Hipposederos ater (18,1 ind/trap/night). The other species with relative similar density were Rhinolopus simplex (10,3 ind/trap/night), Rosettus amplxicaudatus (7,5 ind/trap/night), Miniopterus pusillus (7,3 ind/trap/night), Hipposideros diadema (6,7 in/trap/night), Eonicteris speleae (6.2 ind/trap/night), Phoniscus atrox and Taphozous melanopogon (each of 5,2 ind/trap/night), Macroglossus minimus (4,5 ind/trap/night), Murina cyclotis (4,3 ind/trap/night), Rhinopoma microphyllum (2,7 ind/trap/night), and Hipposideros bicolor (1,1 ind/trap/night). The highest density (27,5 ind/trap/night) of bat was recorded in Raksasa cave Tanjung Ringgit. It followed by density of bat recorded in caves of
\end{abstract}


Gale-gale, Buwun, Pantai Surga, and Kenculit were 25,3 ind/trap/night, 9,3 ind/Trap/night, 8,7 ind/trap/night, and 8,2 ind/trap/night, respectively.

Key words: Bat, Cave, South Region of Lombok Island

\section{PENDAHULUAN}

$\mathrm{P}$ ulau Lombok merupakan salah satu pulau yang memiliki kelimpahan spesies kelelawar cukup tinggi. Hal ini seperti yang di ungkapkan Kitchener, et al. (2002), seorang Angkatan Laut Amerika Serikat telah melakukan penelitian di Pulau Lombok pada tahun 1978-1979. Beberapa spesies kelelawar berhasil diidentifikasi diantaranya Eonycteris spelaea, Dobsonia peronii, Chaerephon plicata, Schotophilus kuhlii dan Myotis muricola. Penelitian dilanjutkan kembali pada tahun 1988 dibeberapa gua yang ada di Pulau Lombok diantaranya di Taman Suranadi (Gua Batu Kota), Batu Koq (Gua Sawa), Pelangan (Gua Pantai berkapur), Kuta (Gua yang berada $4 \mathrm{~km}$ ke arah barat kuta dan gua Gunung Saung) dan Gunung Rinjani (Gua Susu dan Gua Lawa). Hasil penelitian menunjukkan bahwa telah ditemukan 36 spesies kelelawar dan spesies yang paling khas ialah spesies Pteropus lombocensis dan Pipistrellus tenuis swelanus (Kitchener, et al., 2002). Penelitian terbaru yang dilakukan Fajri dan Hadiprayitno (2013) menunjukkan bahwa spesies kelelawar yang ditemukan di Pulau Lombok terdiri dari 6 spesies. Keenam spesies kelelawar tersebut ialah Myotis muricola, Kerivoula hardwickei, Macroglossus minimus, Eonycteris spelaea, Hipposideros diadema dan Hipposideros bicolor.Hipposideros bicolor merupakan spesies kelelawar baru yang belum ditemukan dalam Kitchener, et al. (2002). Dengan ditemukannya kelelawar spesies baru di Pulau Lombok, menambah jumlah kelelawar yang pernah dilaporkan oleh Kitchener, et al. (2002) yaitu sebanyak 36 spesies.

Wilayah Pulau Lombok yang paling banyak ditemukan gua yang dihuni oleh kelelawar ialah wilayah selatan Pulau Lombok, namun informasi spesies kelelawar yang menghuni beberapa gua di wilayah selatan Pulau Lombok belum pernah dilaporkan, justru guan yang ada di wilayah selatan Pulau Lombok belum dilakukan pemanfaatan secara oftimal, hal ini terlihat dari adanya ketidaksesuaian dalam pemanfaatan lahan, penebangan pohon dan penambangan secara liar yang sangat mengganggu dan merusak ekosistem yang ada di wilayah tersebut. Bahkan sudah mulai ditemukan gua-gua yang runtuh (rusak) dan gua yang tidak dihuni oleh kelelawar karena adanya penambangan yang dilakukan oleh masyarakat. Sebagai contoh gua yang ada di wilayah Karst Sekotong Barat.

Dengan demikian, terkait banyaknya gua yang berada di wilayah selatan Pulau Lombok yang dihuni kelelawar, maka dipandang perlu melakukan analisis kelimpahan kelelawar dimasing-masing gua. Mengingat gua yang berada di wilayah selatan Pulau Lombok banyak dimanfaatkan oleh masyarakat yang tidak bertanggung jawab terhadap pemeliharaan habitat gua dan organisme yang menghuni gua-gua tersebut

\section{METODE PENELITIAN Waktu dan Tempat Penelitian}

Penelitiandilaksanakan pada bulan Maret sampai dengan Mei 2014 di lima (5) gua yang ada di wilayah selatan Pulau Lombok yaitu Gua Gale-Gale Lombok Tengah, Gua Buwun Lombok Tengah, Gua Kenculit Lombok Tengah, Gua Raksasa Lombok Timur, dan Gua Pantai Surga Lombok Timur. 


\section{Analisis Kelimpahan Kelelawar}

Data kelimpahan diperoleh pada masing-masing gua, dengan menghitung jumlah mulut gua, tinggi mulut gua dan lebar mulut gua. Jumlah mist net yang terpasang tergantung jumlah mulut gua masing-masing. Pengamatan kelimpahan kelelawar dilakukan selama 3 malam. Berikut pada Tabel 1 adalah keterangan jumlah mulut gua, tinggi mulut gua, dan lebar mulut gua serta jumlah mist net yang dipasang.

Tabel 1. Jumlah Mulut Gua, Tinggi Mulut Gua, dan Lebar Mulut Gua Serta Jumlah Mist Net yang Dipasang

\begin{tabular}{|c|c|c|c|c|}
\hline Lokasi & $\begin{array}{c}\text { Jumlah } \\
\text { Mulut Gua }\end{array}$ & $\begin{array}{c}\text { Tinggi } \\
\text { Mulut Gua } \\
\text { (Meter) } \\
\end{array}$ & $\begin{array}{c}\text { Lebar Mulut } \\
\text { gua } \\
\text { (Meter) } \\
\end{array}$ & $\begin{array}{c}\text { Jumlah } \\
\text { Mist net } \\
\text { Terpasang } \\
\end{array}$ \\
\hline \multirow[t]{3}{*}{ Gua Gale-gale } & & 1. 2,75 & 1. 1,77 & \\
\hline & 3 & 2. 1,85 & 2. 2,35 & 9 \\
\hline & & 3. 3,45 & 3. 3,20 & \\
\hline \multirow[t]{2}{*}{ Gua Buwun } & 2 & 1. 2,50 & 1. 3,80 & 6 \\
\hline & & 2. 3,36 & 2. 4,30 & \\
\hline \multirow[t]{2}{*}{ Gua Kenculit } & 2 & 1. 6,34 & 1. 3,60 & 6 \\
\hline & & 2. 7,78 & 2. 3,25 & \\
\hline \multirow[t]{2}{*}{ Gua Raksasa } & 2 & 1. 9,50 & 1. 4,50 & 6 \\
\hline & & 2. 3,35 & 2. 2,75 & \\
\hline Gua P. Surga & 1 & 5,57 & 6,20 & 3 \\
\hline
\end{tabular}

Kelimpahan kelelawar selanjutnya dianalisis menggunakan rumus yang terdapat pada buku pedoman pengumpulan data keanekaragaman fauna (Suyanto, 1990: 9).

$$
\mathrm{N}=\frac{\text { Jumlah Individu yang Tertangkap }}{\text { Jumlah Mist Net } X \text { malam }}
$$

Keterangan:

N : Kelimpahan Kelelawar

\section{HASIL DAN PEMBAHASAN}

Hasil pengamatan kelimpahan spesies kelelawar gua yang ditemukan di wilayah selatan Pulau Lombok disajikan pada Tabel 2. Hasil perhitungan kelimpahan spesies kelelawar pada Tabel 2 menunjukkan bahwa kelimpahan spesies kelelawar tertinggi ditemukan di Gua
Raksasa Tanjung Ringgit dengan kelimpahan $\quad$ sebesar 27,5 individu/trap/malam. Selanjutnya diikuti oleh Gua Gale-gale 25,3 individu/trap/malam, Gua Buwun 9,3 individu/trap/malam, gua Pantai Surga 8,7 individu/trap/malam, dan gua Kenculit 8,2 individu/trap/malam 
Tabel 2. Kelimpahan Spesies Kelelawar Gua di Wilayah Selatan Pulau Lombok

\begin{tabular}{|c|c|c|c|c|c|c|c|}
\hline \multirow[t]{2}{*}{ No } & \multirow[t]{2}{*}{ Nama spesies } & \multicolumn{5}{|c|}{ Gua } & \multirow{2}{*}{$\begin{array}{c}\mathrm{N} \\
\text { (ind/trap } \\
\text { /malam) }\end{array}$} \\
\hline & & $\begin{array}{c}\text { Gale } \\
- \\
\text { gale } \\
\end{array}$ & $\begin{array}{c}\text { Buwu } \\
\text { n }\end{array}$ & $\begin{array}{c}\text { Kenculi } \\
\mathbf{t}\end{array}$ & $\begin{array}{c}\text { Raksas } \\
\text { a }\end{array}$ & $\begin{array}{l}\text { Panta } \\
\text { i } \\
\text { Surga } \\
\end{array}$ & \\
\hline 1 & Eonycteris speleae & 0,0 & 0,0 & 0,0 & 6,2 & 0,0 & 6,2 \\
\hline 2 & Hipposideros ater & 13,9 & 1,5 & 0,0 & 2,7 & 0,0 & 18,1 \\
\hline 3 & Hipposideros bicolor & 1,1 & 0,0 & 0,0 & 0,0 & 0,0 & 1,1 \\
\hline 4 & Hipposideros diadema & 0,0 & 0,0 & 0,0 & 6,7 & 0,0 & 6,7 \\
\hline 5 & Macroglossus minimus & 0,0 & 0,0 & 0,0 & 4,5 & 0,0 & 4,5 \\
\hline 6 & Miniopterus pusillus & 0,0 & 2,0 & 3,0 & 0,0 & 2,3 & 7,3 \\
\hline 7 & Murina cyclotis & 0,0 & 0,0 & 0,0 & 0,0 & 4,3 & 4,3 \\
\hline 8 & Phoniscus atrox & 0,0 & 3,2 & 0,0 & 0,0 & 2,0 & 5,2 \\
\hline 9 & Rhinolopus simplex & 10,3 & 0,0 & 0,0 & 0,0 & 0,0 & 10,3 \\
\hline 10 & $\begin{array}{l}\text { Rhinopoma } \\
\text { microphyllum }\end{array}$ & 0,0 & 2,7 & 0,0 & 0,0 & 0,0 & 2,7 \\
\hline 11 & $\begin{array}{l}\text { Rosettus } \\
\text { amplxicaudatus }\end{array}$ & 0,0 & 0,0 & 0,0 & 7,5 & 0,0 & 7,5 \\
\hline 12 & $\begin{array}{l}\text { Taphozous } \\
\text { melanopogon }\end{array}$ & 0,0 & 0,0 & 5,2 & 0,0 & 0,0 & 5,2 \\
\hline & (Ind/Trap/malam) & 25,3 & 9,3 & 8,2 & 27,5 & 8,7 & 79,0 \\
\hline
\end{tabular}

Hasil penelitian pada Tabel 2 juga menunjukkan bahwa spesies Hipposederos ater memiliki kelimpahan yang paling tinggi $(18,1$ individu/trap/malam) dibandingkan dengan kelimpahan spesies kelelawar yang lain. kemudian diikuti secara berturut-turut oleh Rhinolopus simplex (10,3 individu/trap/malam), Rosettus amplxicaudatus individu/trap/malam), $(7,5$ pusillus (7,3 individu/trap/malam), Hipposideros diadema $\quad(6,7$ individu/trap/malam), Eonicteris speleae (6,2 individu/trap/malam), Phoniscus atrox dan Taphozous melanopogon (masing-masing memiliki kelimpahan 5,2 individu/trap/malam), Macroglossus minimus $\quad(4,5 \quad$ individu/trap/malam $)$, Murina cyclotis $\quad(4,3$ individu/trap/malam), Rhinopoma microphyllum (2,7 individu/trap/malam), dan Hipposideros bicolor $(1,1$ individu/trap/malam).

Namun demikian, apabila ditelusuri lebih lanjut pada masing-masing gua yang memiliki Hipposederos ater, kelimpahan Hipposederos ater pada masing-masing gua tidak menunjukkan kelimpahan paling tinggi.Hipposederos ater hanya 
menunjukkan kelimpahan tertinggi pada Gua Gale-gale, sedangkan pada gua lain tidak. Pada Gua Buwun dan Gua Raksasa Hipposederos ater memiliki kelimpahan yang paling rendah dan pada beberapa gua seperti Gua Kenculit dan Gua Pantai Surga Hipposederos ater tidak ditemukan keberadaannya.

Spesies kelelawar yang memiliki kelimpahan tertinggi di Gua Buwun ialah Phoniscus atrox individu/trap/malam), diikuti oleh Rhinopoma microphyllum (2,7 individu/trap/malam), Miniopterus pusillus (2,0 individu/trap/malam), dan Hipposederos ater $\quad(1,5$ individu/trap/malam). Spesies kelelawar yang memiliki kelimpahan paling tinggidiGua Kenculit ialah Taphozous melanopogon $(5,2$ individu/trap/malam) dan Miniopterus pusillus memiliki kelimpahan terendah (3,0 individu/trap/malam). Rosettus amplxicaudatus merupakan spesies yang memiliki kelimpahan tertinggi $(7,5$ individu/trap/malam) di Gua Raksasa, selanjutnya diikuti oleh Hipposideros diadema (6,7 individu/trap/malam), Eonicteris speleae $\quad(6,2$ individu/trap/malam), Macroglossus minimus (4,5 individu/trap/malam) dan Hipposederos ater $\quad(4,5$ individu/trap/malam). Kelimpahan spesies kelelawar yang paling tinggi di Gua Pantai Surga ilah Murina cyclotis (4,3 individu/trap/malam), diikuti oleh Miniopterus pusillus (2,3 individu/trap/malam) dan Phoniscus atrox (2,0 individu/trap/malam).

Tingginya kelimpahan kelelawar di Gua Raksasa Tanjung Ringgit disebabkan oleh beberapa faktor diantaranya ialah tingginya kekayaan spesies yang menghuni Gua Raksasa disbanding dengan gua yang lain. Pada Gua Raksasa ditemukan 5 spesies sedangkan digua yang lain ditemukan 2 sampai dengan 4 spesies. Selain itu, ruang gua yang besar, dengan struktur yang unik dengan mikrohabitat yang bervariasi akan membuat gua tersebut dihuni oleh banyak jenis kelelawar. Keadaan gua yang stabil dan jauh dari keramaian dan kebisingan membuat kelelawar semakin aman untuk tinggal dan hidup di dalam gua tersebut. Altringham (1996) menyebutkan, bahwa kondisi gua yang jauh dari kebisingan, gelap, lembab dan suhu yang stabil cocok sebagai tempat beristirahat dan bereproduksi kelelawar.

Kehadiran kelelawar yang tinggi pada suatu gua dapat menguntungan kelelawar yang satu dengan yang lainnya karena keadaan gua yang lembab dan dingin akanmenjadikan mikroklimat gua menjadi stabil. Hal ini sesuai dengan penelitian Baudinette, et al. (1994) yang dilakukan di Gua Kelelawar dan Gua Robertson Australia. Hasil penelitian dikedua gua tersebut membuktikan dalam gua yang dihuni kelelawar dengan jumlah besar dapat menaikkan suhu dalam Gua hingga $3^{\circ} \mathrm{C}$.Pada musim dingin, keadaan ini menguntungkan kelelawar karena mengurangi energi yang diperlukan untuk menghangatkan tubuh.Keuntungan lain yang didapatkan apabila kelelawar hidup dalam koloni besar adalah Menurut Zukal, et al. (2005) beberapa keuntungan hidup dalam koloniadalah adanya transfer informasi, keamanan pada predator, keberhasilanreproduksi, dan thermoregulasi.

Rendahnya kelimpahan kelelawar di Gua Kenculit disebabkan oleh keadaan gua yang sedikit runtuh oleh ombak dan keadaan Gua yang sempit dan berlorong pendek.Runtuhnya gua dapat mengurangi luas hunian tempat bertenggernya kelelawar dalam gua dan kondisi fisik gua yang berubah dari aslinya. Hal ini sesuai dengan pendapat Cox dan More (1995) dalam Wijayanti (2001) yang menyatakan bahwa habitat yag luas akan menampung lebih banyak makhluk hidup di dalamnya dibandingkan dengan habitat yang sempit. 
Ehrlich dan Roughgarden (1987) dalam Wijayanti (2001) menyebutkan bahwa ekosistem yang secara fisik mantap memungkinkan tercapainya komunitas klimaks dalam suksesi sehingga terjadinya penimbunan keragaman biologi yang tinggi sedangkan komunitas yang berubah karena suatu gangguan akan mengalami suksesi kembali (suksesi sekunder), sehingga komunitasnya jauh dari kondisi klimaks.

Secara umum tidak mudah mencari penyebab dari tinggi rendahnya kelimpahan spesies disuatu tempat tertentu dan pada waktu tertentu.Hal ini disebabkan oleh banyaknya faktor-faktor yang mempengaruhi dalam menentukan tinggi/rendahnya kelimpahan suatu spesies dalam suatu populasi (Loiselle dan Blake, 1992).

Berdasarkan Tabel 2, menunjukkan bahwa Hipposederos ater memiliki kelimpahan yang paling tinggi (18,1 individu/trap/malam) dibandingkan dengan kelimpahan spesies kelelawar yang lain. Wijayanti (2011) juga pernah menyebutkan, bahwa Hipposideros ater di Gua Petruk juga memiliki kelimpahan tinggi dengan jumlah individu tertangkap sebanyak 135 individu. Hipposideros ater merupakan spesies yang dapat beradaptasi dalam berbagai habitat, sehingga akan memungkinkan Hipposideros ater memiliki kelimpahan tertinggi dari pada spesies kelelawar lainnya.

Hipposideros ater masuk dalam daftar IUCN Red List 2014 dengan setatus Least Concern (CL) atau paling sedikit informasinya. Spesies kelelawar yang lain dalam penelitian ini yang masuk dalam daftar IUCN Red List 2014 dengan status Least Concern (CL) atau paling sedikit informasinya ialah Hipposideros diadema, Miniopterus pusillus, Macroglossus minimus, dan Rhinopoma microphyllum. Masuknya spesies-spesies tersebut dalam daftar IUCN Red List 2014 dengan status paling sedikit disebabkan oleh menurunnya jumlah individu atau populasi. Spesies yang masuk daftar IUCN dengan status paling sedikit memiliki distribusi yang luas, dapat beradaptasi pada berbagai habitat, dan umumnya berada pada kawasan lindung. Namun berbeda halnya dengan hasil penelitian ini, menunjukkan bahwa spesies-spesies yang masuk daftar IUCN Red List 2014 dengan status paling sedikit justru memiliki kelimpahan individu cukup tinggi seperti Hipposideros diadema (6,7 Individu/Trap/Malam), Miniopterus pusillus (7,3 Individu/Trap/Malam), Macroglossus minimus (4,5 Individu/Trap/Malam), dan Rhinopoma microphyllum (2,7 Individu/Trap/Malam). Hal ini tentu disebabkan oleh gua yang sebagai habitat spesies kelelawar berada pada kondisi habitat yang stabil, baik fisik, ketersediaan pakan dan mikroklimat yang sesuai serta jauh dari kebisingan. Altringham (1996) menyebutkan bahwa kondisi gua yang jauh dari kebisingan, gelap, lembab dan suhu yang stabil cocok sebagai tempat beristirahat dan bereproduksi kelelawar. Dengan kondisi demikian kelelawar dapat berlindung dari pemangsa, mencegah evaporasi, menjaga suhu tubuh dan berkembang biak dengan aman. Tingginya kelimpahan spesies tertentu di suatu tempat menujukkan bahwa spesies yang bersangkutan ada kecenderungan lebih mendominasi dibandingkan spesies yang lain, serta mengindikasikan adanya kesesuaian spesies tersebut dengan potensi habitat di dalam menyediakan sumber makanan, perlindungan dan tempat melakukan aktivitas lainnya.

\section{SIMPULAN}

Sejumlah gua di wilayah selatan Pulau Lombok NTB dihuni oleh 12 spesies dari 6 Famili kelelawar. Spesies tersebut diantaranya: Hipposederos ater memiliki kelimpahan yang paling tinggi (18,1 individu/trap/malam) dibandingkan 
dengan kelimpahan spesies kelelawar yang lain. kemudian diikuti secara berturut-turut oleh Rhinolopus simplex (10,3 individu/trap/malam), Rosettus amplxicaudatus

$(7,5$ individu/trap/malam), Miniopterus pusillus $\quad(7,3 \quad$ individu/trap/malam $)$, Hipposideros diadema $\quad(6,7$ individu/trap/malam), Eonicteris speleae (6.2 individu/trap/malam), Phoniscus atrox dan Taphozous melanopogon (masing-masing memiliki kelimpahan 5,2 individu/trap/malam), Macroglossus minimus (4,5 individu/trap/malam), Murina cyclotis $\quad(4,3$ individu/trap/malam), Rhinopoma microphyllum (2,7 individu/trap/malam), dan Hipposideros bicolor $(1,1$ individu/trap/malam). Kelimpahan spesies kelelawar tertinggi ditemukan di Gua Raksasa Tanjung Ringgit dengan kelimpahan sebesar 27,5 individu/trap/malam. Selanjutnya diikuti oleh Gua Gale-gale 25,3 individu/trap/malam, Gua Buwun 9,3 ind/trap/malam, gua Pantai Surga 8,7 individu/trap/malam, dan gua Kenculit 8,2 individu/trap/malam.

\section{DAFTAR PUSTAKA}

Altringham, J.D. 1996. BATS. Biologi and Behaviour.Oxford University Press. New York.

Baudinette, R.V., S.K. Churchill, K.A. Christian, J.E. Nelson \& P.J. Hudson. 2000. Energy, Water Balance And The Roost Microenvironment In Zukal, J., H. Berkova, dan Z. Rehak. 2005. Activity shelter selection by Myotismyotis and Rhinolophus
Three Australian Cave-Dwelling Bats (Microchiroptera). J. Comp. Physiol. $B$, 170: 439-446.

Fajri, S.R. dan Hadiprayitno, G. 2013. Kelelawar Pulau Lombok. Prosiding Seminar Nasional Penelitian dan Pembelajaran Sains. Program Pascasarjana Pendidikan IPA. Mataram.

Kitchener D.J., Boeadi, L. Charlton, dan Maharadatunkamsi. 2002. Mamalia Pulau Lombok. Bidang Zoologi Puslit Biologi-LIPI, The Gibbon Foundation Indonesia, PILI-NGO Movement. Bogor

Loiselle, B.A. dan J.G. Blake. 1992.Population Variation In A Tropical Bird Community. Journal Bioscience, 42 (11):838-845.

Suyanto, A. 2001.Kelelawar Indonesia. Puslitbang Biologi LIPI. Jakarta

Suyanto, A. $1990 . \quad$ Pedoman Pengumpulan Data Keanekaragaman Fauna. Puslitbang Biologi LIPI. Jakarta

Wijayanti, F. 2001. Komunitas fauna Gua Petruk dan Gua Jatijajar Kabupaten kebumen Jawa Tengah. Tesis.Progam Pasca Sarjana Universitas Indonesia. Jakarta.

Wijayanti, F. 2011. Biodiversitas dan Pola Pemilihan Sarang Kelelawar: Studi Kasus di Kawasan Karst Gombong Kabupaten Kebumen Jawa Tengah. Institut Pertanian Bogor. hipposideros hibernating in the katerinska cave.Journal Mam Biol.70:271-281 